\title{
The State of Our World After a Generation of Climate Change 'Inaction'
}

\author{
William John Montague* \\ Independent Data Scientist, Montreal, Canada \\ *Corresponding Author: William John Montague, Independent Data Scientist, \\ Montreal, Canada.
}

\section{Content summary: Dire warning!}

The increases in fossil fuel extraction every year over year in this century speak volumes. Millions of years worth of ancient sequestered hydrocarbons, consumed as energy with the resulting compounds being added to our biosphere has overwhelmed the natural cycles. It is impossible to measure and assign responsibility for world wide carbon emissions nation by nation. It is also impossible to track the emissions generated by the governments and corporations doing the extraction and production because all of them lie. Rising atmospheric levels of carbon dioxide every single year over year of the twenty first century sadly show the lack of truth in voluntary national emissions reporting which are supposed to be the basis of the Paris accord. There is now thirty three percent more carbon dioxide in the atmosphere than when I was born in 1954 and even in this past year of pandemic travel shutdowns, that number is still going up.

It is not so difficult to check the financial statistics of global hydrocarbon production. Every step taken back from what was agreed at Kyoto is already causing increasing the human death toll from global warming somewhere, today. We have been and still are continuously increasing the levels of carbon dioxide accumulations in the biosphere at ever greater rates decade over decade for more than seventy years. Any claims of being on track for containing global warming within the agreed one point five degree temperature increase range where we are still capable of sustaining human life world wide, ring hollow as the world's glaciers melt at ever greater rates.
Received: May 03, 2021

Published: May 25, 2021

(C) All rights are reserved by William John

Montague.
The good news

It is not too late to change our course. There is still a chance to stop 'runaway' global warming, if we clean up our act now! Now means by the end of this decade. We simply have to choose to decide to stop spewing combustion emissions into the biosphere. Please note I am not saying we need to stop burning all fossil fuels. There are many places in the world where it will continue to make sense to do so, even coal. What I am saying is we need to put an end to the waste emissions.

\section{The better news}

There is a viable sustainable way to do this worldwide. There exists what I will be polite and call an unknown to modern science, branch of electricity, which is capable of creating an electrical environment suitable for accomplishing the intended purposes. We can easily use this technology to manufacture a truly clean burning replacement for hydrocarbon fuels as well as break apart carbon dioxide gas molecules. I refer to Nikola Tesla's Longitudinal Electric Waves which travel in the so called 'vacuum of space', exactly like sound waves travel in air. The basic functionality of this aspect of electrical science is explained by Tesla's Ozone Generator, US Patent 568177, (Issued in 1896 or 125 years ago).

I am aware that our modern laws of electricity tell us that longitudinal electric waves do not exist. This little understood phenomena, however, is now known to occur within what we call the Plasma state of gaseous matter, which astronomers tell us is the state of most matter in the universe. It is of note that within such a plasma our 'laws of electricity' break down. It turns out we do find Tesla's

Citation: William John Montague. "The State of Our World After a Generation of Climate Change 'Inaction'". Acta Scientific Microbiology 4.6 (2021): $85-86$. 
longitudinal electric waves occurring in a gas plasma exactly where Tesla said he first observed them more than a hundred and thirty years ago and long before the 'laws' were written. Tesla's Electric Force can be easily and economically be generated in the appropriate manners to facilitate the dissociation of normally inert and electrically neutral linear gas molecules. This means diatomic gas molecules such as atmospheric oxygen or nitrogen. Carbon dioxide is also a linear molecule.

\section{The bad news}

Complete lack of interest as in refusing to even acknowledging the possibility of this world changing technology indicates to me that current world leadership has no intention of permitting any breakthrough technology from disrupting their hydrocarbon energy economic plans.

\section{The worse news}

If we did actually follow the current 'Net Zero 2050' proposal of planting trees to offset emissions we will guarantee that much of our world dies within the lifetimes of those born in this century. I say this simply because thirty percent of annual carbon dioxide emissions and most of the excess combustion heat goes straight into the oceans which cover three quarters of our planet. Life as we know it and depend on in our oceans simply can not take this anymore.

\section{Recommendation}

Immediately implement Nikola Tesla's longitudinal wave electrostatic technology to provide the entire world with the capability to manufacture a clean burning replacement for hydrocarbon fuels made from atmospheric nitrogen. This needs to be done before becomes too late to stop runaway global warming. The intellectual property belonged to Nikola Tesla and he was very clear that he left this legacy to be shared in peace by the entire world. This technology is not about any one specific machine. Tesla's Longitudinal Electric Wave Technology will change everything and no one nation or corporation or individual can own it.

From the outset in my quest for a climate change solution, it was self evident that any viable world wide solution to climate change would be very disruptive to the current economic policies of global trade driven by hydrocarbon energy. I believe that such a disruptive technology is the only way for effecting a global climate solution simply because of the sheer amounts of energy required to both clean things up and to run our civilizations. To be successful, any climate solution must first resolve the access to energy inequalities in such obvious evidence throughout our world.

That I can not find anybody that even wants to try and stop global warming is to me a very sad comment. What does it mean that no one anywhere even wants to try and stop global warming. No one else that I am aware of has proposed anything else which offers any chance of success. If anyone reading this really does want to preserve a livable future both for their children and for all human civilizations all around our planet, I am hoping to hear from you that you are going to do this.

Tesla has already designed, built, tested, patented and documented all the parts needed to do this. I am ready to assist you with design and assembly of a safely built apparatus as I must mention that there is a very real danger of electrocution. When working with these necessarily high voltages and high frequencies of alternation there are necessary design precautions that must be taken into account in order to stay safe. If you doubt what I say because you do not know who I am or where I come from, my answer is that if you really can't find anyone who can comprehend Tesla's very explicit instructions, I am available. Nothing would make me happier that to show anyone who cares about saving our world exactly how this application of Tesla's longitudinal waves of electrostatic force can be put.

\section{Volume 4 Issue 6 June 2021 \\ (C) All rights are reserved by William John Montague.}

